University of Nebraska - Lincoln

DigitalCommons@University of Nebraska - Lincoln

1979

\title{
An Objective Forecast Method Developed for Lake Ontario Induced Snowfall Systems
}

\author{
K. F. Dewey \\ University of Nebraska- Lincoln, kdewey@unl.edu
}

Follow this and additional works at: https://digitalcommons.unl.edu/natrespapers

Part of the Natural Resources and Conservation Commons, Natural Resources Management and Policy Commons, and the Other Environmental Sciences Commons

Dewey, K. F., "An Objective Forecast Method Developed for Lake Ontario Induced Snowfall Systems" (1979). Papers in Natural Resources. 1286.

https://digitalcommons.unl.edu/natrespapers/1286

This Article is brought to you for free and open access by the Natural Resources, School of at DigitalCommons@University of Nebraska - Lincoln. It has been accepted for inclusion in Papers in Natural Resources by an authorized administrator of DigitalCommons@University of Nebraska - Lincoln. 


\title{
An Objective Forecast Method Developed for Lake Ontario Induced Snowfall Systems
}

\author{
K. F. DEWEy \\ Climatology Program, Universily of Nebraska, Lincoln 68588 \\ (Manuscript received 13 September 1978, in final form 19 February 1979)
}

\begin{abstract}
A research effort was initiated in 1976 to develop an objective lake-effect snowfall forecast model for each of the Great Lakes. It is the purpose of this paper to present the development and evaluation of the forecast method which was created for the Lake Ontario induced snowfall systems. All Lake Ontario lake-effect days were identified for a 10-year period prior to the 1976 snowfall season. Upper air and surface observations were combined with overlake data for these lake-effect periods. The dominant predictors were derived through the diagnostic ability of stepwise multiple discriminant analysis. The final product of this research effort was a seven-predictor lake-effect intensity forecast method which was evaluated on an experimental basis during the 1976-77 and $1977-78$ snowfall seasons.
\end{abstract}

\section{Introduction}

Each winter, the region to the lee of the Great Lakes is subjected to the occurrence of lake-effect snow storms. Synoptically, the lake-effect system develops when cold and stable arctic (or polar) air passes over the relatively warmer lake surface. The turbulent exchange of heat and moisture into the lower layers of the advected air mass acts as the stimulus for the production of mesoscale convective processes. The once stable air mass becomes temporarily unstable with superadiabatic lapse rates near the water surface. The response to this energy flux is the initiation of the characteristic snow squalls or flurries. As the convective activity is advected inland, it interacts with synopticscale atmospheric processes as well as with surface features. According to Hill (1971), annual snowfall increases by $13-20 \mathrm{~cm}$ for every $30 \mathrm{~m}$ of rise to the lee of the Great Lakes. Paine and Kaplan (1971) illustrated that the development of a secondary trough and positive vorticity advection (some cyclonic curvature) over the Great Lakes will have a significant influence on the development of the lake-induced snowfall systems. Therefore, the intensity of the lake-effect system is not simply a function of the turbulent exchange of energy between the lake and the atmosphere, for surface and synoptic-scale features can also act to either enhance or attenuate the magnitude of the system.

If this turbulent exchange of energy persists and is combined with favorable synoptic-scale conditions, heavy snowfall can occur to the lee of the lakes which severely cripples transportation and communications in the lake-effect snowbelt. Several studies have presented dramatic accounts of how severe these meso- systems can be during exceptionally strong arctic outbreaks (Dewey, 1977; Sykes, 1966; and, Wiggin, 1950). A five-day lake-effect storm in January 1966, for example, deposited a total of $259 \mathrm{~cm}$ (102 inches) of snow at Oswego, New York, and a lake-effect storm on 9 January 1976 produced $178 \mathrm{~cm}$ (68 inches) of snow in less than $24 \mathrm{~h}$ at Adams, New York. Numerous studies (e.g., Eichenlaub, 1970; Holroyd, 1971 ; Muller, 1966; Strommen and Harman, 1978) have illustrated that the lake-induced clouds can extend inland as much as $400 \mathrm{~km}$ from the lake. However, the heavier snowfalls are generally limited to an area within $150 \mathrm{~km}$ of the lake shoreline. Fig. 1 illustrates the classic nature of the lake-effect system. Cold arctic air is being advected across the lower Great Lakes on 30 November 1976 with the visible result-bands of clouds streaming inland to the lee of Lakes Michigan, Huron, Erie and Ontario. The area to the south and east of Lakes Erie and Ontario is snow covered as a result of a frontal system having passed through the region several days earlier.

Even though these systems can produce intense snowfalls, they are of mesoscale dimensions. Because of this limited spatial extent, the lake-effect system has not been given much attention during the development of National Weather Service forecast guidance products. An examination of the Forecasting Handbook (Riech et al., 1976) reveals that there are no centrally produced guidance products for the intensity of lakeeffect systems. Forecasts of heavy snow are issued for a $12 \mathrm{~h}$ period (6-18 $\mathrm{h}$ after initial data time) for the conterminous United States; however, this guidance package is prepared for the general synoptic-scale 


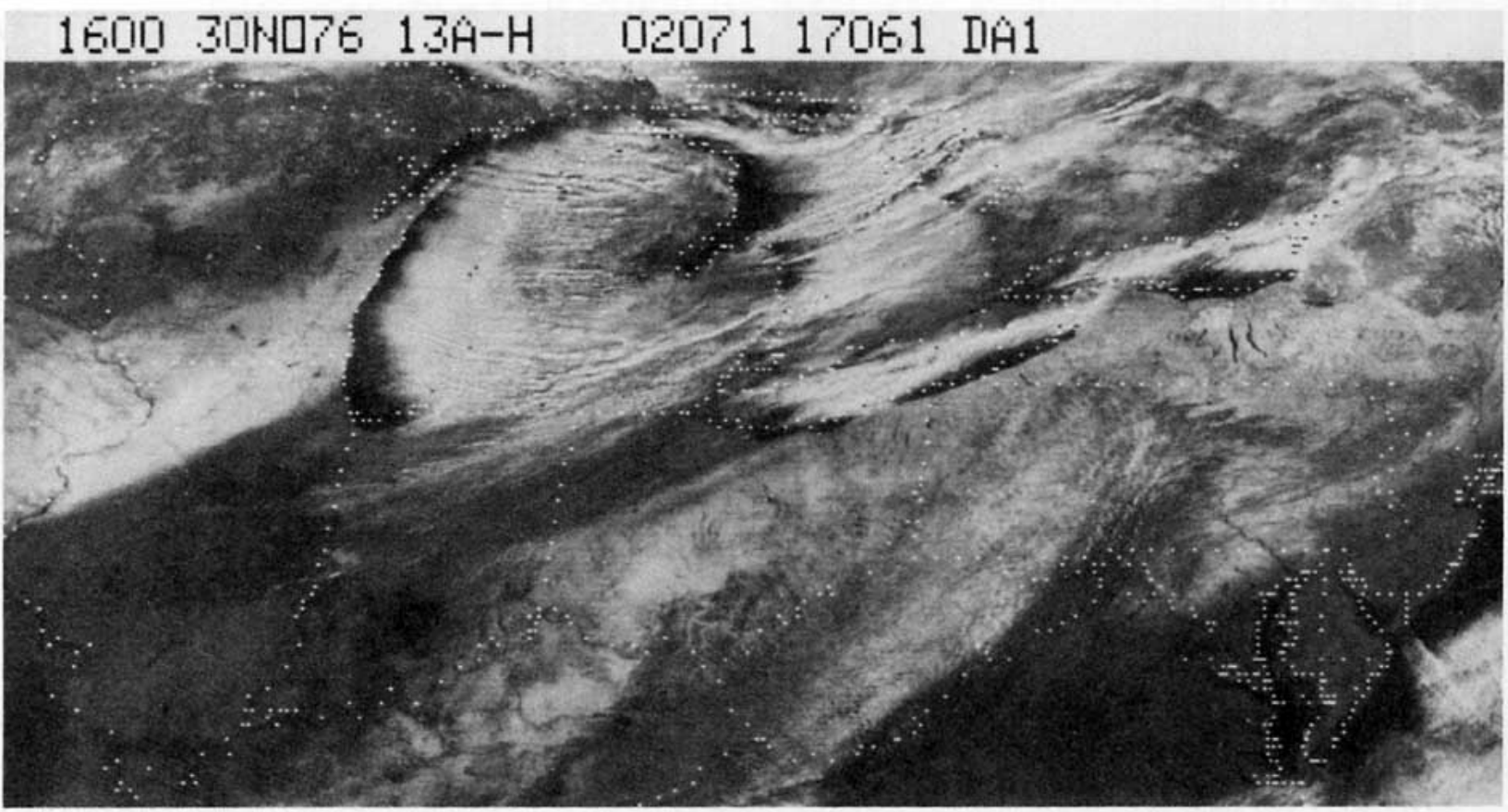

FIG. 1. Satellite photograph of 30 November 1976 illustrating the bands of lake-induced clouds streaming inland to the lee of the Great Lakes.

(frontal or cyclonic induced) snowfall. Fig. 2 illustrates a $12 \mathrm{~h}$ forecast of synoptic-scale heavy snowfall for the Ohio River Valley region. The phrase "Lcly Hvy Snow" will also be added to the chart (with arrows pointing to the affected area) when the forecaster preparing the chart at the National Meteorological Center subjectively interprets that the forecast period exhibits a potential for orographically induced or lake induced heavy snowfall. However, it should be noted that the arrows which are illustrated in Fig. 2 are for a singleintensity, subjective forecast. It is significant to note that NWS personnel at several forecast offices have devised nomograms and tables (based on local em-

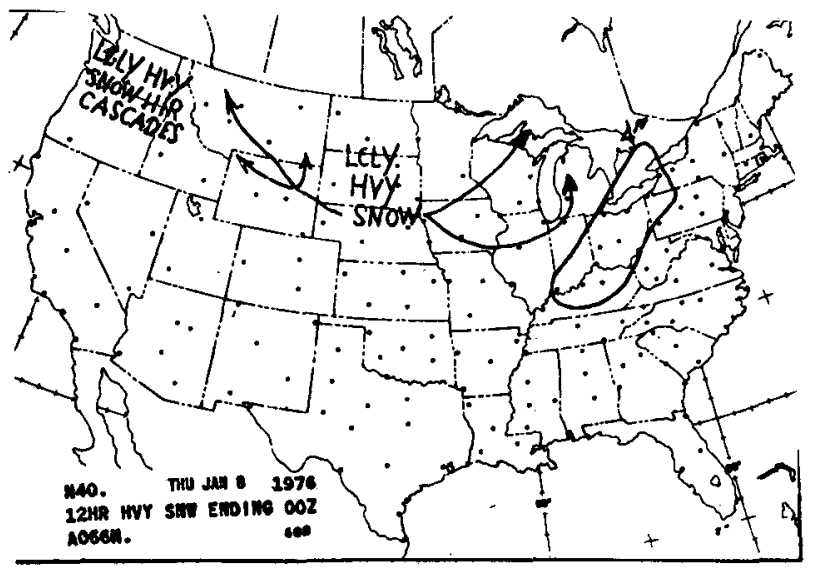

FIG. 2. Short-range heavy snow guidance forecast available on the National Weather Service facsimile system. pirical data) for use as guidance during occurrences of lake-effect snowfall.

A research effort was initiated in 1976, within the Techniques Development Laboratory (National Weather Service, Silver Spring, Maryland), to develop an automated lake-effect forecast guidance product. It was the original intention of this study to produce a forecast method which could be used for lake-effect systems induced by any of the Great Lakes. It became apparent that due to the differing topography to the lee of each lake, the variation in lake dimensions and the difference in predictor significance (ice cover, for example, is far more significant on Lake Erie than it is on Lake Ontario) the same predictors and predictor coefficients would not be universally compatible for each of the Great Lakes. Therefore, a lake-effect forecast model was developed for each of the lakes with a slightly different list of pre-

TABLE 1. Observed snowfall intensities during lake-effect periods (November 1967-March 1976).

\begin{tabular}{cc}
\hline $\begin{array}{c}\text { Observed maximum } \\
24 \text { h snowfall }\end{array}$ & $\begin{array}{c}\text { Lake Ontario systems } \\
\text { number of days analyzed }\end{array}$ \\
\hline No snow & 29 \\
$\leqslant 2.5 \mathrm{~cm}$ ( $\leqslant 1$ inches) & 23 \\
$2.5-10 \mathrm{~cm}(1-4$ inches) & 50 \\
$10-20 \mathrm{~cm}$ (4-8 inches) & 59 \\
$20-30 \mathrm{~cm}$ (8-12 inches) & 58 \\
$30-60 \mathrm{~cm}(12-24$ inches) & 45 \\
$>60 \mathrm{~cm}$ (>24 inches) & 18 \\
\hline
\end{tabular}


TABLE 2. Regression equations used to estimate overwater air temperature and dew-point fields (Phillips, 1972).

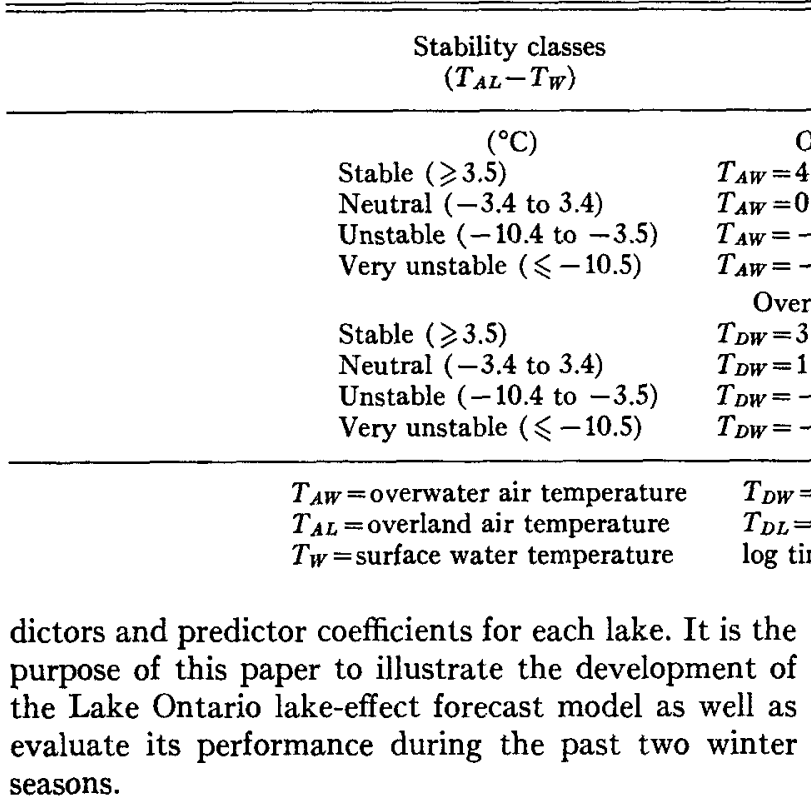

\section{Research methodology}

All Lake Ontario lake-effect snowfall events which had occurred during the 10-year period November 1967 through March 1976 were isolated. Utilizing a procedure outlined by Strommen (1975), climatological data and surface charts were examined to determine which days had temperatures lower than the lake surface temperatures and which days did not have synoptic-scale precipitation occurring in the area. In this manner, all non-lake-effect days as well as lakeeffect days which occurred concurrently with synopticscale precipitation events were excluded. Due to the inability of determining the magnitude of the lakeeffect component during synoptic events, this latter exclusion was necessary.

The climatological data records were examined, and each $24 \mathrm{~h}$ period was classified into one of seven observed snowfall amounts. The classification was based upon the maximum observed $24 \mathrm{~h}$ snowfall in the region downwind and within $150 \mathrm{~km}$ of the lake. Table 1 lists the distribution of observed lake-effect snowfall intensities for Lake Ontario. The category of "No snow" was included for it became apparent that on several occasions during lake-effect events, the energy flux in combination with the planetary boundary layer conditions was not quite large enough to initiate precipitation processes.

A search was then begun to determine which predictors were responsible for the observed variation in intensity of these snowfall systems. Based upon previous lake-effect investigations (Dewey, 1975; Jiusto and Kaplan, 1972; Lavoie, 1972; Paine and Kaplan, 1971), 21 predictors were chosen for the initial statistical
Regression equations
Overwater air temperature $\left({ }^{\circ} \mathrm{C}\right)$

$4.21+0.48 T_{A L}+0.47 T_{W}-1.82 \log$ time

$4.21+0.48 T_{A L}+0.47 T_{W}$
$0.61+0.49 T_{A L}+0.52 T_{W}$

$=-0.26+0.79 T_{A L}+0.73 \log$ time $+0.24 T_{W}$

Overwater dew-point temperature $\left({ }^{\circ} \mathrm{C}\right)$

erwater dew-point temperature $\left({ }^{\circ} \mathrm{C}\right)$
$=3.41+0.40 T_{D L}+0.51 T_{W}-1.10 \log$ time

1.04+0.73T $T_{D L}+0.13 T_{W}$

$T_{D W}=$ overwater dew-point temperature

$T_{D L}=$ overland dew-point temperature

time $=\log$ of duration of air over water $(\mathrm{min})$.

anslysis. Many of the predictors already existed within the National Meteorological Center (NMC) computer system. These NMC predictors are based on observations collected on the synoptic scale; however, the lake-effect event is of mesoscale dimensions which necessitated the development, and inclusion in the model, of several mesoscale predictors.

The procedure employed in this diagnostic phase of the research was the calculation or estimation of predictor values which were valid for the same time period as the predictand values. Therefore, observed predictor values averaged over each $24 \mathrm{~h} \mathrm{(1200-1200}$ GMT) period were directly compared to the observed maximum snowfall amounts for the same period. The total list of possible predictors included the wind speed at the surface upwind of the lake as well as at several levels over Lake Ontario. The amount of fetch over the water for the advecting air mass was measured at two levels over the lake through the use of observed surface and $850 \mathrm{mb}$ wind directions. The values of two stability indices (George's $K$ Index and the Lifted Index) at Buffalo, New York, were also included in this stage of the investigation. The average relative humidity of the air mass from the surface to $500 \mathrm{mb}$ was available as a predictor and the saturation deficit at $850 \mathrm{mb}$ was calculated using the observed conditions at Buffalo. The ice cover (as a percentage of total possible) on Lake Ontario was also included as a potentially significant predictor. Finally, several estimates of the vertical and horizontal mesoscale thermal and moisture gradients near the lake were included in the initial statistical analysis.

The largest problem in estimating the energy fluxes over and near the lake was the availability of overlake data. However, through the use of a series of regression equations (Table 2), which were developed by Phillips (1972), it was possible to estimate the air temperature and dew-point fields at $2.5 \mathrm{~m}$ over the lake. The lake surface temperatures which were necessary for these equations were acquired from the National Environ- 


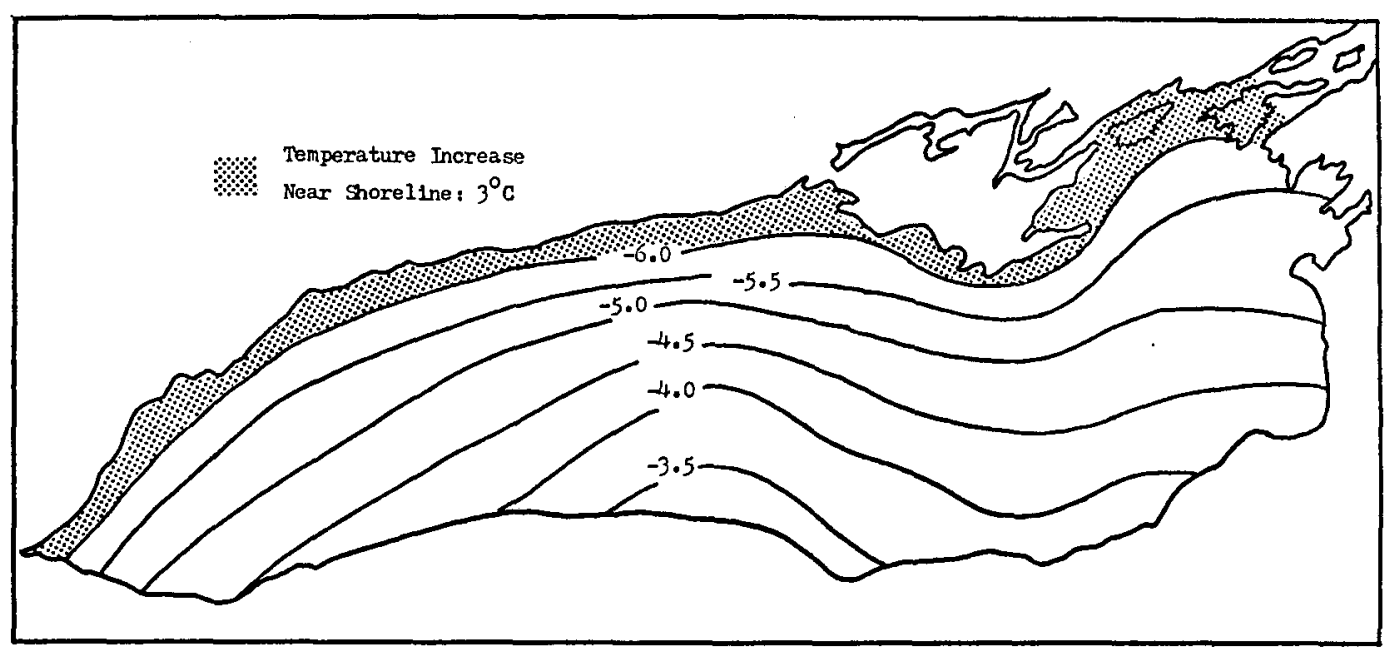

FIG. 3. Estimate of air temperature $T_{A W}\left({ }^{\circ} \mathrm{C}\right)$ over Lake Ontario.

mental Satellite Service satellite-measured lake sufface temperatures and the Atmospheric Environment Service-Canada airborne radiometer lake temperature surveys. The upwind temperatures $T_{A L}$ were measured along the windward side of the lake and using the equations presented in Table 2 , the spatial pattern of $T_{A W}$ could be presented as illustrated in Fig. 3 . For use as a predictor, $T_{A W}$ refers to the spatial average over the entire lake surface. It was then possible to estimate the thermal and vapor-pressure gradient between the lake surface and the $2.5 \mathrm{~m}$ boundary layer for each of the lake-effect days. It was possible, by using upper air data, to estimate the vertical energy gradient between the lake surface and several upper levels. Wind speeds over the lake were estimated from upwind data and overlake stability classifications as illustrated by Richards et al. (1966). Although this research effort concentrated on the lower atmospheric modification occurring over and quite near the lake, Baker (1976) illustrated that it is possible to measure the lakeinduced changes in temperature and dew-point fields well downstream from the lake.

The data were then subjected to multiple discriminant analysis. The value of this statistical technique in meteorological research was well described by Miller (1962). A standard version of this statistical routine was acquired from the UCLA Biomedical Computer facilities (Dixon, 1976) and entered into the local computer system. The snowfall amounts for each lakeeffect day in the 10-year study period were known beforehand, so it was not the object at this point to predict intensity levels. Instead, the discriminant analysis program examined the predictor values within each of the seven groups for each $24 \mathrm{~h}$ period in order to determine if the combination of predictor values was statistically different from group to group. This initial test was, in essence, a test of whether the predictors chosen for the model could discriminate between the various snowfall categories. It was expected that there might be some collinearity between predictors; therefore, a "stepwise" predictor screening procedure was incorporated into the statistical program. The predictor which offered the most ability to discriminate between groups was selected first and the procedure was replicated until the last predictor (the one with the least additional ability to discriminate) was chosen. As each predictor entered the equation, its ability to discriminate was evaluated in conjunction with the previously entered predictors. It was possible to set a statistical limit beyond which a predictor would be eliminated due to its lack of offering additional discriminating ability. A level of significance of $\alpha=0.05$ was chosen for the $F$ test included within this statistical routine and the initial list of predictors was trimmed to the seven predictors listed in Table 3.

Although the magnitude of the $F$ values in Table 3 have no particular significance, the relative significance of each predictor can be evaluated by means of a ranking of the $F$ scores. An examination of this ranking in Table 3 reveals that the predictor which offers the

TABLE 3. Predictors which were utilized in the final forecast model.

\begin{tabular}{lc}
\hline \multicolumn{1}{c}{ Predictor } & $\begin{array}{c}F \text {-value for } \\
\text { inclusion* }\end{array}$ \\
\hline 1. $T_{W}-T_{850}$ (temperature of the water & \\
$\quad-$ temperature at $850 \mathrm{mb}$ ) & 22.55 \\
2. Surface wind fetch over the lake & 8.89 \\
3. Percent ice cover on the lake & 7.05 \\
4. Surface wind velocity over the lake & 4.26 \\
5. e $e_{a}$ (vapor pressure gradient at & \\
2.5 m over the lake) & 4.06 \\
6. Wind fetch at 850 mb over the lake & 4.00 \\
7. Relative humidity, surface to $500 \mathrm{mb}$ & \\
$\quad$ (Buffalo radiosonde) & 3.28 \\
\hline
\end{tabular}

* Significant $F$-value for inclusion at $\alpha=0.05=2.13$. 
TABLE 4. Example of forecast probabilities generated for the Lake Ontario lake-effect snowbelt. Italicized numbers indicate categories chosen in forecast selection.

\begin{tabular}{|c|c|c|c|c|c|c|}
\hline \multicolumn{7}{|c|}{3 January 1978} \\
\hline $\begin{array}{l}\text { No snow } \\
0.1 \%\end{array}$ & $\begin{array}{c}\leqslant 2.5 \mathrm{~cm} \\
0.8 \%\end{array}$ & $\begin{array}{r}2.5-10 \mathrm{~cm} \\
3.2 \%\end{array}$ & $\begin{array}{r}10-20 \mathrm{~cm} \\
16.3 \%\end{array}$ & $\begin{array}{r}20-30 \mathrm{~cm} \\
20.5 \%\end{array}$ & $\begin{array}{r}30-60 \mathrm{~cm} \\
38.5 \%\end{array}$ & $\begin{array}{r}>60 \mathrm{~cm} \\
20.6 \%\end{array}$ \\
\hline \multicolumn{7}{|c|}{10 January 1978} \\
\hline $\begin{array}{l}\text { No snow } \\
0.1 \%\end{array}$ & $\begin{array}{c}\leqslant 2.5 \mathrm{~cm} \\
2.2 \%\end{array}$ & $\begin{array}{r}2.5-10 \mathrm{~cm} \\
6.4 \%\end{array}$ & $\begin{array}{r}10-20 \mathrm{~cm} \\
10.0 \%\end{array}$ & $\begin{array}{r}20-30 \mathrm{~cm} \\
34.4 \%\end{array}$ & $\begin{array}{r}30-60 \mathrm{~cm} \\
43.1 \%\end{array}$ & $\begin{array}{r}>60 \mathrm{~cm} \\
3.8 \%\end{array}$ \\
\hline
\end{tabular}

greatest amount of ability to discriminate between snowfall amounts is $T_{w}-T_{850}$ (temperature of the water surface-temperature at $850 \mathrm{mb}$ ). It is significant to note that this key predictor was previously examined by Holroyd (1971) in his study of lake-effect cloud bands and $850 \mathrm{mb}$ temperatures. Holroyd illustrated that nearly all lake-effect storms occurred when the $850 \mathrm{mb}$ temperature was more than $13^{\circ} \mathrm{C}$ colder than the lake surface temperature. Unfortunately, this earlier study was not extended to include an analysis of the magnitude of snowfall during the lake-effect occurrences. The multiple discriminant analysis program was run once more with just these seven predictors for the purpose of deriving predictor coefficients for each of the snowfall categories.

\section{Evaluation of the forecast method during the 1976-77 and 1977-78 winter seasons}

The implicit assumption in the use of multiple discriminant analysis is that if it is statistically possible to discriminate between the categories in the data sample, the same predictors and attendent coefficients can be utilized to produce discrete probability forecasts for each of the categories on a real-time basis. The next and final step in this study was the testing of the discriminant analysis equations and coefficients (which had been developed from the 10-year data base) during the 1976-77 and 1977-78 winter seasons.

A $24 \mathrm{~h}$ forecast of snowfall extending from 12001200 GMT was issued for each lake-effect day. The data for the forecast equations were a combination of predictors which are automatically produced by the National Meteorological Center and latest available values for those predictors not automatically predicted. The MOS (Model Output Statistics) surface wind forecasts were used to determine the airstream trajectory over the lake and hence, the average fetch of the surface wind over the lake. The PE (Primitive Equation) model $850 \mathrm{mb}$ trajectory forecasts were utilized to determine the average fetch of airstreams across the water at the $850 \mathrm{mb}$ level. The forecast mean relative humidity of the air mass over Lake Ontario was derived from the six-layer PE numerical prediction model. The surface wind velocity over the lake during the forecast period was estimated using the forecast MOS surface winds combined with the equations pro- duced by Richards et al. (1966) and recently verified by Phillips and Irbe (1978). The temperature at $850 \mathrm{mb}$ for the forecast period was made available in the PE model $850 \mathrm{mb}$ temperature and associated parcel trajectory forecast. The latest available surface water temperatures were combined with these $850 \mathrm{mb}$ temperatures to estimate the average thermal gradient between these two layers. The average vapor pressure gradient between the surface of the lake and the $2.5 \mathrm{~m}$ boundary layer was estimated using the MOS forecasts of $\mathrm{Max} / \mathrm{Min}$ temperatures, latest available lake surface temperatures, and the equations outlined by Phillips (1972). The percentage of ice cover was determined from the latest available satellite ice reconnaissance charts which were available on the national facsimile network.

It should be noted that this is a conditionally operative model which was employed only when the following three criteria were satisfied: (i) the expected wind direction put the area south and east of Lake Ontario downwind of the lake; (ii) the forecast air temperatures were expected to be less than the lake surface temperatures; and (iii) there was no large-scale frontal precipitation expected within the vicinity of the lake.

The statistical relationship

$$
P_{(k)}=\exp (f k) / \sum^{k} \exp (f i, k)
$$

was utilized for the forecasts of lake-effect intensity, where $P_{(k)}$ is the probability of membership in group $k, f k$ is the discriminant index for group $k$, and $\sum^{k} \exp (f i, k)$ is the sum of the discriminant index values for all groups $i-k$. This equation produced a discrete probability for each group and a forecast was made based upon the group with the highest probability. As previously indicated, the snowfall amounts used in the creation of the discriminant equations were based on the maximum observed snowfall to the lee of the lake. Therefore, the forecasts during the two-year period of testing were for $24 \mathrm{~h}$ maximum snowfall amounts. The actual forecasts provided guidance for determining the most likely maximum intensity of the lake-effect system. The area affected by the lake-effect storm would vary from occurrence to occurrence based upon the surface wind conditions. Therefore, the forecast (and verification) area would be different with 
TABLE 5. Two season (1976-77 and 1977-78) forecast verifications for the Lake Ontario lake-effect snowfall model.

\begin{tabular}{|c|c|c|c|c|c|c|c|}
\hline \multirow{2}{*}{$\begin{array}{l}\text { Observed } \\
\text { group }\end{array}$} & \multicolumn{7}{|c|}{ Predicted group } \\
\hline & No snow & $\leqslant 2.5 \mathrm{~cm}$ & $2.5-10 \mathrm{~cm}$ & $10-20 \mathrm{~cm}$ & $20-30 \mathrm{~cm}$ & $30-60 \mathrm{~cm}$ & $>60 \mathrm{~cm}$ \\
\hline No snow & 2 & 一 & 3 & - & - & - & - \\
\hline$\leqslant 2.5 \mathrm{~cm}$ & - & 5 & 3 & - & - & - & - \\
\hline $2.5-10 \mathrm{~cm}$ & 1 & 3 & 12 & 2 & - & 1 & - \\
\hline $10-20 \mathrm{~cm}$ & - & 2 & 6 & 12 & 3 & 2 & 1 \\
\hline $20-30 \mathrm{~cm}$ & - & - & 1 & 2 & 8 & 6 & 3 \\
\hline $30-60 \mathrm{~cm}$ & - & - & - & 1 & 1 & 7 & 4 \\
\hline$>60 \mathrm{~cm}$ & - & . - & - & - & 一 & - & 2 \\
\hline
\end{tabular}

$\mathrm{P}=$ Predicted group, $\mathrm{O}=$ observed group.' Number of days $(\mathrm{P}-\mathrm{O})>1$ classification category $=15=16 \%$ of the forecasts. Number of days $(\mathrm{P}-\mathrm{O})>2$ classification categories $=2=2 \%$ of the forecasts.

northerly winds than with westerly winds. However, in all cases, it was assumed that the significant snowfalls would occur within $150 \mathrm{~km}$ of the shoreline. Table 4 illustrates an example of the forecast probabilities which were generated for the Lake Ontario lake-effect snowbelt. A forecast of $30-60 \mathrm{~cm}$ (12-24 inches) was selected for both of these days due to the highest forecast probability occurring within that snowfall intensity level. The maximum snowfall observed to the lee of Lake Ontario on 3 January 1978 was $53 \mathrm{~cm}$ (21 inches) at Hooker, New York, and on 10 January 1978 was $46 \mathrm{~cm}$ (18 inches) at Bennett Bridge, New York.

The observed snowfall amounts for the two-year testing period were made available from the Environmental Data Service, National Climatic Center, Asheville, North Carolina, and were compared to the forecast snowfall amounts. It is difficult to measure the relative success of this forecast product for there are no other operational lake-effect intensity forecast models available for comparative purposes. A measure of this forecast method's success can be illustrated, however, through a subjective evaluation of the forecast verifications.

Table 5 illustrates that only $16 \%$ of the verifications were more than one classification category from the predicted intensity of snowfall; and the forecast error exceeded two classification categories only $2 \%$ of the time. It is significant to note that on no occasion was there a complete failure of the model (i.e., a forecast of category 1 with a verification of category 7 ). It is interesting to note that the model had a tendency to overforecast snowfall amounts. While $18 \%$ of the verifications exhibited an underforecasting bias, $30 \%$ exhibited an overforecasting bias. The exceptional ice cover on Lake Ontario during the last two winter seasons can perhaps be linked to this overforecasting bias. The average maximum Lake Ontario ice cover in the 10-year data sample which was utilized to create the predictor coefficients was $16 \%$ with the greatest extent of $25 \%$ ice cover being observed during the winter of 1973-74. Rondy (1971), in his Great Lakes Ice Allas, also points out that the normal maximum extent of ice on Lake Ontario is only $15 \%$. However, the maximum ice cover on Lake Ontario during the past two winter seasons (both of which had record breaking cold weather in the Great Lakes region) was $42 \%$ on 15 February 1977 and $45 \%$ on 20 February 1978. Although the extensive ice cover on Lake Ontario limited the intensity of the lake-effect system during these past two winters, the relatively low coefficient weighting for ice cover in the Lake Ontario model did not allow the model to adequately assess the significance of this predictor during this period of exceptional ice cover.

\section{Summary}

An operational lake-effect snowfall intensity forecast model was developed for Lake Ontario systems. Climatological data, surface observations and upper air data were collected, and overlake data were generated for all lake-effect periods which occurred between November 1967 and March 1976. These lake-effect occurrences were divided into $24 \mathrm{~h}$ periods and stratified into seven intensity levels of maximum observed snowfall. Stepwise multiple discriminant analysis was employed, and the conclusion was reached that by using a combination of seven predictors, it should be possible to forecast intensity of the lake-effect system. During the past two winter seasons, the model was tested for its forecast significance. An evaluation of the forecast verifications indicated that the model performed quite well with a slight tendency for over-forecasting (which was related to the anomalous ice cover on Lake Ontario).

Since there is no centrally produced lake-effect intensity guidance product, the individual forecast offices have had to rely on local experience for the forecasting of lake-effect activity. The forecast method described in this paper can produce an automated forecast of lake-effect snowfall with a discrete probability of occurrence for each of seven snowfall intensities. It is anticipated that this model could provide assistance to the various lake-effect forecast offices. The model will be further evaluated during the 1978-79 snowfall season. 
Acknowledgments. Appreciation is extended to Dr. Glahn and the entire staff of the Techniques Development Laboratory, National Weather Service, Silver Spring, Maryland, for their assistance and the use of their facilities in the development of this forecast model.

\section{REFERENCES}

Baker, D., 1976: The mesoscale temperature and dew-point fields of a very cold airflow across the Great Lakes. Mon. Wea. Rev., 104, 860-867.

Dewey, K., 1975: The prediction of Lake Huron lake-effect snowfall systems. $J$. Appl. Meteor., 14, 3-7.

- 1977: Lake-effect snowstorms and the record breaking 1976-77 snowfall to the lee of Lakes Erie and Ontario. Weatherwise, 30, 228-231.

Dixon, W., 1976: Biomedical Computer Programs. University of California Press, Los Angeles, 600 pp.

Eichenlaub, V., 1970: Lake-effect snowfall to the lee of the Great Lakes -its role in Michigan. Bull. Amer. Meteor. Soc., 51, 403-412.

Hill, J. 1971: Snow squalls in the lee of Lake Erie and Lake Ontario-a review of the literature. NOAA Tech. Memo. NWS ER-43, National Weather Service, Eastern Region, Garden City, NY, 20 pp.

Holroyd, E., 1971 : Lake-effect cloud bands as seen from weather satellites. J. Atmos. Sci., 28, 1165-1170.

Jiusto, J., and M. Kaplan, 1972 : Snowfall from lake-effect storms. Mon. Wea. Rev., 100, 62-66.

Lavoie, R., 1972: A mesoscale numerical model of lake-effect storms. J. Atmos. Sci., 29, 1025-1040.

Miller, R. G., 1962 : Statistical Prediction by Discriminant Analysis. Meteor. Monog., No. 24, Amer. Meteor. Soc., 1-54.
Muller, R., 1966 : Snowbelts of the Great Lakes. Weatherwise, 19, 248-257.

Paine, D., and M. Kaplan, 1971: The linking of multi-scaled energy sources creating a severe winter storm. Preprints 7th Conf. Severe Local Storms, Kansas City, Amer. Meteor. Soc., 299-306.

Phillips, D., 1972: Modification of surface air over Lake Ontario in winter. Mon. Wea. Rev., 100, 662-670.

- , and J. Irbe, 1978: Lake to land comparison of wind, temperature and humidity on Lake Ontario during the International Field Year for the Great Lakes. Atmospheric Environment Service-Canada, publ. CLI-2-77, $51 \mathrm{pp}$. [Available from the AES, Downsview, Ontario.]

Richards, T., H. Dragert, and D. McIntyre, 1966: Influence of atmospheric stability and over-water fetch on winds over the lower Great Lakes. Mon. Wea. Rev., 94, 448-453.

Riech, R., A. Sadowski, and J. Harrell, Editors, 1976: National Weather Service Forecasting Handbook No. 1-Facsimile products. U. S. Department of Commerce, NOAA, Washington, D.C.

Rondy, D., 1971: Great Lakes Ice Atlas. NOAA Tech. Memo. NOS LSCR 1, Great Lakes Environ. Res. Lab., Ann Arbor, 6 pp. 35 plates. [NTIS COM-71-01052.]

Strommen, N., 1975: Seasonal change in the axis of maximum lake-snow in western Lower Michigan. Ph.D. dissertation, Michigan State University, 113 pp.

- - and J. Harman, 1978: Seasonally changing patterns of lake-effect snowfall in western Lower Michigan. Mon. Wea. Rev., 106, 503-509.

Sykes, R., 1966: The blizzard of 1966 in central New York-a legend in its time. Weatherwise, 19, 241-247.

Wiggin, B., 1950: Great snows of the Great Lakes. Weatherwise, $3,123-126$. 